\title{
Anti gastritic and antiulcerogenic effects of Solanum nigrum in laboratory animals
}

\author{
Maddala Rajeswari ${ }^{1, ~ *, ~ S u b b u l a k s h m i ~ G u r u m u r t h y ~}{ }^{1}$, Sandhya Kamat ${ }^{2}$ \\ ${ }^{1}$ Department of Foods, Nutrition and Dietetics, College of Home Science, University of Mumbai, Mumbai, India \\ ${ }^{2}$ Department of Pharmacology, GS Seth Medical College and KEM Hospital, Mumbai, India
}

\section{Email address:}

rajeswariradhakrishna@gmail.com(M. Rajeswari)

\section{To cite this article:}

Maddala Rajeswari, Subbulakshmi Gurumurthy, Sandhya Kamat. Anti Gastritic and Antiulcerogenic Effects of Solanum Nigrum in Laboratory Animals. International Journal of Nutrition and Food Sciences. Vol. 2, No. 6, 2013, pp. 266-271.

doi: 10.11648/j.ijnfs.20130206.11

\begin{abstract}
Leaves and berries of Solanum nigrum are commonly used in South India for the treatment of gastric ulcers, gastritis and other gastric problems. The present study investigated the Solanum nigrum leaf and berry extracts for their protective effect on ethanol induced gastritis and aspirin induced gastric ulcers of pylorus ligated rats. Sucralfate and Ranitidine were used as standard Drugs. Oral administration of aqueous extract of leaf $(80 \mathrm{mg} / \mathrm{Kg}$ and $250 \mathrm{mg} / \mathrm{Kg}$ respectively) and berry $(50 \mathrm{mg} / \mathrm{Kg})$ significantly reduced the concentration of Evans blue in both gastric contents and glandular tissue indicating decreased vascular permeability and mucosal damage with respect to that of control. The berry aqueous extract offered more protection against gastritis than the leaf extracts. Pretreatment with aqueous extracts of Leaf $(250 \mathrm{mg} / \mathrm{Kg})$ and berry $(50 \mathrm{mg} / \mathrm{Kg})$ significantly reduced the Ulcer Index. The results tend to confirm the popular use of the plant.
\end{abstract}

Keywords: Solanum Nigrum, Gastritis, Gastric Contents, Glandular Tissue, Gastric Ulcers, Pyloric Ligation, Ulcer Index

\section{Introduction}

Use of medicinal foods is an ancient Indian form of medicine used by tribes and older generations. After a lapse of century it is gaining much importance due to less severe side effects and its holistic approach towards health. In traditional medicine, several plants and foods have been used to treat gastro intestinal disorders including ulcers [1]. Studies on cabbage previously employed as an anti ulcer agent in folk medicine, has led to the development of gefarnate [2], which acts by enhancing the gastric mucosal strength [3]. Banana fruit was found to inhibit peptic ulceration [4]. Similarly large cardamom (Fruit of Amomum subulatum Roxb) and its ethyl acetate fraction seemed to exhibit protective effect on gastric mucosal barrier [5]. Oral administration of black tea (Camellia sinensis) extract has also been found to reduce the incidence of gastric erosions [6].

One among such oft spoken medicinal plants is Solanum nigrum used as a vegetable in few South Indian states like Tamilnadu and Karnataka. It is an annual herb belonging to the family of Solanaceae with leaves alternate, simple, smooth margins, flowers small, white or pale violet in color, fruit being a dull black berry as small as a pepper growing in clusters. Solanum nigrum is well known for its efficiency in curing gastro intestinal, liver and kidney disorders. The berry is preserved in salt and used in a preparation called kolumbu by the local people. Therefore the present study was aimed at confirming the therapeutic effect of Solanum nigrum as an anti gastritic and antiulcer food in folk medicine.

\section{Materials and Methods}

\subsection{Preparation of Plant Extracts}

Plant material was procured from Bangalore from a single source for all the experiments after authentification by a Botanist. The leaves and berries were separated after thorough cleaning. They were partially shade dried, dehydrated at a temperature of $60^{\circ} \mathrm{C}$ and then powdered. Aqueous and hydro alcoholic extracts were prepared using the dehydrated powders. For the preparation of aqueous extract, $20 \mathrm{~g}$ of each of the test material was soaked in $100 \mathrm{ml}$ of water for $24 \mathrm{hrs} .100 \mathrm{ml}$ of water was added and boiled for 10 minutes, cooled it and filtered through whatman no. 1 filter paper. The extract was made up to $100 \mathrm{ml}$. For the 
preparation of hydro alcoholic extract, $20 \mathrm{gm}$ of plant samples were soaked in $100 \mathrm{ml}$ of $1: 1$ water and ethanol and same method was employed as mentioned above. For administration, the hydro alcoholic extract was suspended in $0.5 \%$ carboxy methyl cellulose (CMC).

\subsection{Animals}

Female albino rats of Sprague-Dawley strain weighing between 180 to $200 \mathrm{~g}$ were kept under standardized conditions before their use for the experiment. The animals were fed with standard commercial pellet diet and water ad libitum. Coprophagy was prevented by housing the rats in raised mesh bottom cages.

\subsection{Experimental Design I}

Anti gastritic effect of Solanum nigrum was tested on ethanol induced mucosal damage in rats and quantified by Evans Blue technique. A total of 63 rats were used in this study. All the rats were divided in to 9 groups randomly, comprising of 7 in each group. After 24 hrs. of fasting, all the groups were administered with different treatments described as following. I

Group 1: Distilled water (D/W) served as negative control

Group 2: Sucralfate at a dose of $360 \mathrm{mg} / \mathrm{Kg}$ [7] served as positive control

Group3: Leaf aqueous extract (LAE) with lower dose (80 $\mathrm{mg} / \mathrm{Kg})$

Group4: Leaf aqueous extract (LAE) with higher dose (250 mg/Kg)

Group5: Berry aqueous extract (BAE) with a dose of $50 \mathrm{mg} / \mathrm{Kg}$

Group6: CMC served as negative control II

Group7: Leaf hydro alcoholic extract (LHAE) with lower dose $(80 \mathrm{mg} / \mathrm{Kg})$

Group8: Leaf hydro alcoholic extract (LHAE) with higher dose $(250 \mathrm{mg} / \mathrm{Kg})$

Group9: Berry hydro alcoholic extract (BHAE) with a dose of $50 \mathrm{mg} / \mathrm{Kg}$

The lower dose $(80 \mathrm{mg} / \mathrm{Kg})$ was selected on the basis of consumption of Solanum nigrum leaves as vegetable and the higher dose $(250 \mathrm{mg} / \mathrm{Kg})$ was as recommended by ayurvedic physicians in South India. The dosage for berry powder was extrapolated from the recommended dose range for humans [8]. Groups of rats treated with hydro alcoholic extracts of leaves and berry were compared with the CMC treated group. After 25 minutes of treatment with test extracts, standard drug and controls, all the rats were injected with Evans blue through femoral vein $(1 \mathrm{mg} / 100 \mathrm{gm})$. After 5 minutes, Absolute ethanol ( $1 \mathrm{ml} / 200 \mathrm{gm})$ was given orally and the animals were sacrificed after $10 \mathrm{~min}$. of ethanol administration. The extent of damage following 10 minutes of exposure to ethanol was measured in this study by using the method described by Szabo et al.[9]. The stomach tissue and contents were removed for estimation of Evans blue. Extraction and estimation of Evans blue from gastric tissue and contents were carried out by the method of Beach and Steinetz [10].

\subsection{Experimental Design II}

Anti ulcerogenic effect of Solanum nigrum was investigated in aspirin induced pylorus ligated rats. A total of about 40 rats were used for this experiment. The rats were divided in to four groups consisting of 10 animals in each group. After $24 \mathrm{hrs}$. of fasting, all the groups were administered with different treatments described as following.

Group 1: Distilled water (D/W) which served as negative control

Group 2: Ranitidine at a dose of $50 \mathrm{mg} / \mathrm{Kg}$ served as positive control

Group3: Leaf aqueous extract (LAE) with a dose of 250 $\mathrm{mg} / \mathrm{Kg}$

Group4: Berry aqueous extract (BAE) with a dose of 50 $\mathrm{mg} / \mathrm{Kg}$

Pylorus was ligated after 30 minutes of treatment with extracts, positive and negative controls. The operative procedure described by Shay et al.[11] was used for pyloric ligation. Aspirin $(500 \mathrm{mg} / \mathrm{Kg})$ suspended in $1 \% \mathrm{CMC}$ in water was given orally to all the groups of rats 15 minutes after pyloric ligation and drinking water was withheld. After 7 hours the animals were sacrificed and the stomachs removed after clamping the esophagus. The stomach was cut along the greater curvature and washed gently under tap water and then examined for severity of ulceration according to the following scale:

$0=$ normal grey colored stomach, $0.5=$ pink to red coloration of stomach, $1=$ spot ulcer, $1.5=$ hemorrhagic streak, $2=$ ulcer $<5,3=$ ulcers $>5,4=$ ulcers with bleeding. Mean ulcer scores for each treatment groups was calculated and expressed as ulcer Index [12].

\subsection{Chemical Analysis}

Qualitative phytochemical tests were carried out to identify the main constituents of extracts. Tests for steroids, triterpenoids, saponins, flavonoids, Cardiac glycosides, furano coumarins, isoflavones, lignans, phenolic acids, anthra and naphtha quinones were carried out according to the methods of Harborne [13]. Nutrients and Tannins were analyzed in Leaf and berry powders. Minerals and vitamins were estimated by the methods of Raghuramulu et al. [14], Soluble and insoluble fiber by the method of AOAC [15] and tannin content by the method of Ranganna [16].

\subsection{Statistical Analysis}

Data was statistically analyzed on computer using SPSS statistical package. ANOVA and Scheffe test were applied to test the significance

\section{Results}

\subsection{Anti Gastritic Effect}


The Evans blue concentration in gastric contents and glandular tissue of animals which were treated with sucralfate, leaf aqueous extracts, berry aqueous and hydro alcoholic extracts 30 mins prior to the oral administration of ethanol were significantly lower when compared to controls. Table 1. Shows that the leaf aqueous extracts at dose levels of $80 \mathrm{mg} / \mathrm{Kg}$ as well as $250 \mathrm{mg} / \mathrm{Kg}$ significantly $(\mathrm{p}<0.05)$ reduced the concentration of Evans blue in both gastric contents and glandular tissue. Both the doses of leaf hydro alcoholic extracts though decreased Evans blue leakage in gastric contents as compared to CMC treated group, this decrease was not statistically significant. With respect to berries, both the aqueous and hydro alcoholic extracts at dose levels of $50 \mathrm{mg} / / \mathrm{kg}$ significantly reduced the concentration of Evans blue in both gastric contents and glandular tissue.

Table.1. Evans blue concentration in gastric contents and glandular tissue

\begin{tabular}{lll}
\hline Treatment group & $\begin{array}{l}\text { Gastric } \\
\text { content }\end{array}$ & Glandular Tissue \\
\hline Group 1(D/W) & $19.39 \pm 1.08$ & $24.05 \pm 1.16$ \\
Group 2 (Sucralfate) & $5.10 \pm 1.19^{\mathrm{a}}$ & $14.36 \pm 1.58^{\mathrm{a}}$ \\
Group 3 (LAE 80mg/Kg) & $10.84 \pm 1.55^{\mathrm{a}}$ & $16.56 \pm 1.8^{\mathrm{a}}$ \\
Group 4 (LAE 250mg/Kg) & $6.27 \pm 0.94^{\mathrm{a}}$ & $14.80 \pm 1.02^{\mathrm{a}}$ \\
Group 5 (BAE) & $5.12 \pm 1.42^{\mathrm{a}}$ & $11.03 \pm 1.12^{\mathrm{a}}$ \\
Group 6 (CMC) & $17.08 \pm 4.37$ & $23.47 \pm 1.62$ \\
Group 7 (LHAE $80 \mathrm{mg} / \mathrm{Kg})$ & $12.78 \pm 1.63$ & $22.14 \pm 1.42$ \\
Group 8 (LHAE 250mg/Kg) & $12.40 \pm 2.55$ & $22.19 \pm 2.45$ \\
Group 9 (BHAE) & $4.37 \pm 1.42^{\mathrm{b}}$ & $10.79 \pm 0.90^{\mathrm{b}}$ \\
\hline
\end{tabular}

Values are expressed as Mean \pm S.E, a significant $(<0.05)$ compared to negative control I $(\mathrm{D} / \mathrm{W}),{ }^{\mathrm{b}}$ significant $(<0.05)$ compared to negative control II (CMC)

Table 2. shows that the percentage reduction of the concentration of Evans blue after treatment with different doses of leaf aqueous extracts revealed a dose dependent relationship. A maximum reduction was recorded in sucralfate, berry aqueous and hydro alcoholic extract treated groups.

Table.2. \% reduction in Evans blue concentration in gastric contents and glandular tissue when compared with negative controls D/W and $C M C$

\begin{tabular}{lll}
\hline Treatment group & Gastric content Glandular Tissue \\
\hline Group 1(D/W) & 75 & 42 \\
Group 2 (Sucralfate) & 36 \\
Group 3 (LAE $80 \mathrm{mg} / \mathrm{Kg})$ & 44 & 38 \\
Group 4 (LAE 250mg/Kg) & 69 & 64 \\
Group 5 (BAE) & 75 & \\
Group 6 (CMC) & & 8 \\
Group 7 (LHAE $80 \mathrm{mg} / \mathrm{Kg})$ & 24 & 8 \\
Group 8 (LHAE 250mg/Kg) & 30 & 64 \\
Group 9 (BHAE) & 76 & \\
\hline
\end{tabular}

\subsection{Anti Ulcerogenic Effect}

Administration of aspirin $(500 \mathrm{mg} / \mathrm{Kg})$ orally in pylorus ligated rats induced severe ulceration in gastric mucosa. In the stomachs of control group of rats treated with aspirin after pyloric ligation, $80 \%$ of rats showed extensive hemorrhagic ulcers and $20 \%$ showed focal ulcers along with lymphoplasmocytic infiltrations. In the groups treated with ranitidine, nearly $80 \%$ of the rats did not show ulcer formation except for a few which presented with edema, inflammation and congestion. In the groups treated with Leaf aqueous extracts, $60 \%$ of rats did not have ulcers whereas in the groups treated with Berry aqueous extract $80 \%$ did not have ulcers (Figure 1).

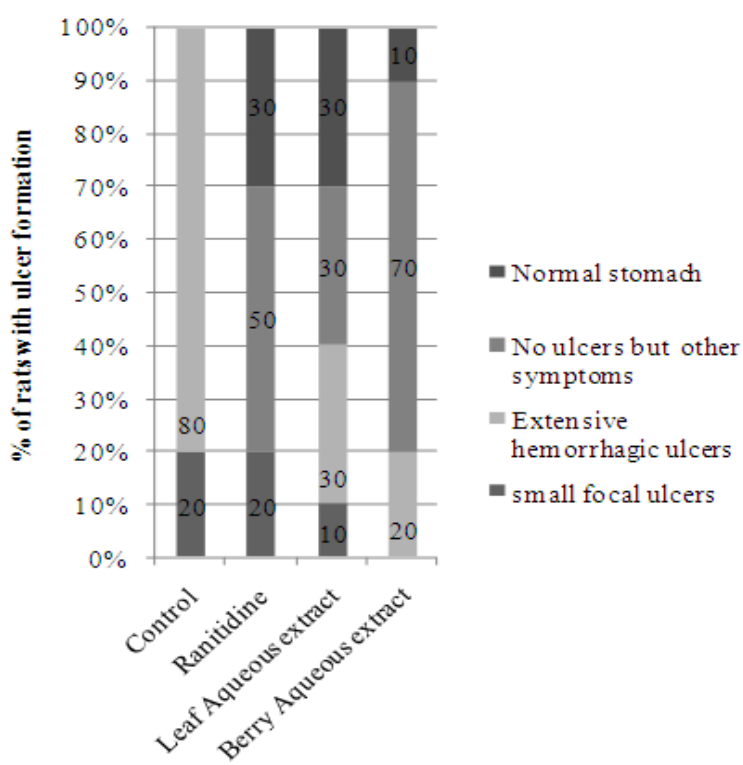

Figure 1. \% of rats with different types of ulcer formation in the treatment groups

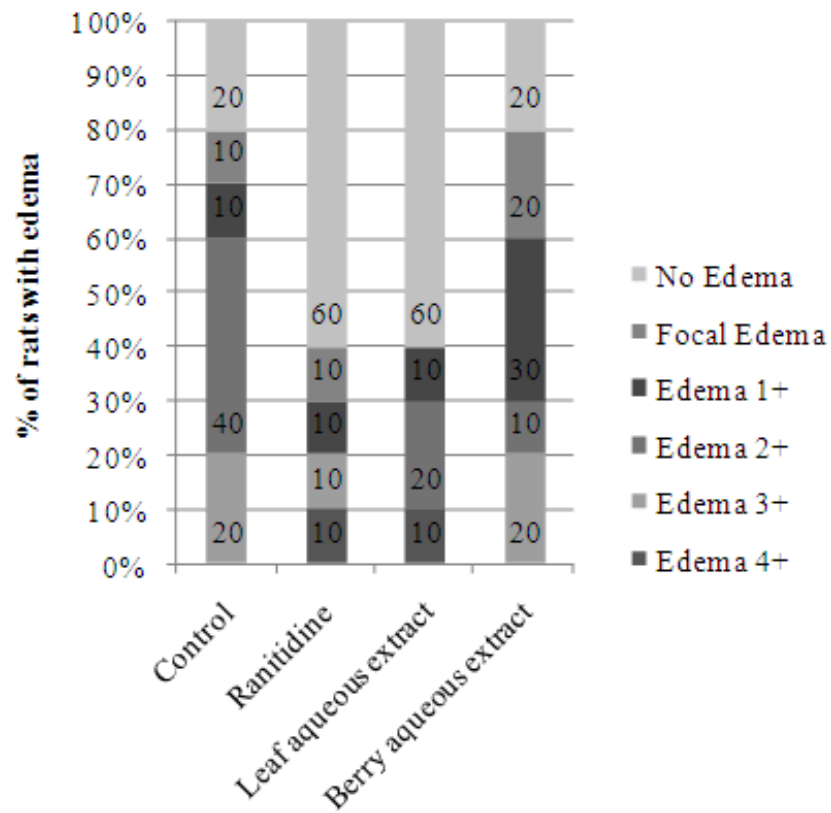

Figure 2. \% of rats with different grades of edema in the treatment groups 
When the edematous symptoms were observed, $80 \%$ of rats presented with different grades of edema and $20 \%$ did not have edema in the control group. In the groups treated with Ranitidine and Leaf aqueous extracts, $60 \%$ of rats did not show edema while $40 \%$ showed different grades of edema. In the groups treated with berry aqueous extracts, 20\% of rats did not show edema while $80 \%$ had different grades of edema (Figure 2). From Table 3. it is evident that pretreatment with ranitidine, aqueous extracts of leaf (250 $\mathrm{mg} / \mathrm{Kg})$ and berry $(50 \mathrm{mg} / \mathrm{Kg})$ significantly reduced ulcer Index with respect to control group. The protective effect of fruit aqueous extract was equivalent to that of Ranitidine in reducing ulcer Index. There was no significant reduction observed in the volume of gastric juice

Table.3. Effect of Ranitidine and Solanum nigrum extracts on volume of gastric juice and Ulcer Index

\begin{tabular}{lll}
\hline Treatment group & $\begin{array}{l}\text { Volume of Gastric juice } \\
\text { ml/100g }\end{array}$ & Ulcer Index \\
\hline Group 1(D/W) & $3.42 \pm 0.13$ & $4.60 \pm 0.53$ \\
Group 2(Ranitidine) & $1.10 \pm 0.12$ & $1.45 \pm 0.43^{\mathrm{a}}$ \\
Group 3(LAE 250 mg/Kg) & $3.1 \pm 0.10$ & $2.65 \pm 0.33^{\mathrm{a}}$ \\
Group 4 (BAE 50 mg/Kg) & $2.8 \pm 2.03$ & $1.50 \pm 0.41^{\mathrm{a}}$ \\
\hline
\end{tabular}

Values are expressed as Mean \pm S.E, ${ }^{\text {a }}$ significant $(<0.05)$ compared to negative control $(\mathrm{D} / \mathrm{W})$

\subsection{Chemical Analysis}

In the present study, steroids, triterpenoids, saponins, flavonoids, cardiac glycosides, isoflavones, phenolic acids and amino acids were found to be present in trace amounts in leaf and berry aqueous as well as hydro alcoholic extracts. The tannin content of leaves was higher $(7.3 \mathrm{mg} \%)$ than that of berries $(3.5 \%)$. The leaves were found to contain more amounts of calcium, iron, zinc $\beta$-carotene and soluble fiber than the berries. The berries were found to have more amount of Vitamin $C$ than the leaves (Table 4).

Table. 4. Nutritive value of Solanum nigrum leaf and berry dehydrated powders (per 100g)

\begin{tabular}{lll}
\hline Nutrient & Leaf & Berry \\
\hline p-carotene(mg) & 25.8 & 2.2 \\
Thiamine(mg) & 1 & 2.2 \\
Riboflavin(mg) & 0.8 & 0 \\
Vitamin C(mg) & $8.4^{\mathrm{a}}$ & 32.2 \\
Folic acid( $\mu \mathrm{g})$ & 111.9 & 55.9 \\
Calcium(mg) & 1256.5 & 343.1 \\
Phosphorus(mg) & 1388.8 & 1934.8 \\
Iron(mg) & 34 & 11.8 \\
Zinc(mg) & 6.5 & 5.1 \\
Copper(mg) & 1.2 & 1.2 \\
Soluble Fiber(gm) & 31.2 & 25.2 \\
Insoluble Fiber(gm) & 1.8 & 4.2 \\
\hline
\end{tabular}

\section{Discussion}

Chemical or restraint stress induces gastric vascular injury and leads to increased vascular permeability resulting in mucosal hemorrhage and erosions. Ethanol induced gastric lesion formation may be due to stasis in gastric blood flow which contributes to the development of hemorrhage and necrotic aspects of tissues injury [17].

The oxygen free radical induced lipid peroxidation (LP) is one of the various mechanisms implicated in the pathogenesis of acute ethanol induced gastric mucosal lesions in rats. Continuous ethanol ingestion for 5 days caused chronic mucosal injury characterized by marked alterations in plasma membranes from gastric mucosa. Increased free radicals and LP levels were due to gastritis as indicated by increased mucosal glutathione content along with decreased thymidine kinase activity showing decreased cell proliferation [18]. Another mechanism explains that intra gastric administration of ethanol to rats causes significant gastric mucosal damage, accompanied by elevated expression of cyclooxygenase-2(COX-2) and inducible nitric oxide synthase (Inos) as well as transient activation of redox-sensitive transcription factors, such as NF-kappaB and AP-1 and mitogen activated protein kinases (MAPKs)[19]. Thus ethanol is a potent gastritis agent causing deleterious effects on gastric mucosa. Despite these challenging effects produced by ethanol, sucralfate and Solanum nigrum extracts were found to ameliorate these effects which is vivid from the reduction in Evans blue concentration in the present investigation.

The standard drug sucralfate offers protection by locally forming a layer covering ulcers and erosions which inhibit diffusion of $\mathrm{H}+$ ions and pepsin to the damaged mucosa. Sucralfate binds pepsin and bile acids, also seems to have stimulating effect on the release of prostaglandins and the regeneration of epithelial cells in the gastric mucosa [20]. Sucralfate causes elevation of mucosal blood flow, activates Nitric Oxide (NO) and prostaglandin systems thus contributing to mucosal integrity, preservation of mucosal micro circulation and gastro protective action [21]. The protective effect of leaf aqueous and berry extracts observed were similar to sucralfate and the mechanism of action may also be similar to that mediated by sucralfate.

Non-steroidal anti- inflammatory drugs (NASAIDs) like aspirin induce ulceration by inhibition of biosynthesis of cytoprotective prostaglandins PGEs and PGI2 ( by inhibition of cyclooxygenase pathway of arachidonic acid metabolism), resulting in over production of leukotrienes and other products of 5-lipoxygenase pathway. Oral dose of aspirin might produce a dose-dependent increase in the area of gastric lesions accompanied by a significant increase in blood neutrophils, infiltration into mucosa, leukotriene B4 formation and almost complete suppression of prostaglandin synthesis [22].

Leukotriene antagonists and 5-lipoxygenase inhibitors are capable of inhibiting alcohol and NASAID induced gastric ulceration [23]. Therefore the protection afforded by the leaf 
and fruit aqueous extracts could be due to inhibition of 5-lipoxygenase pathway or due to Leukotriene's antagonistic activity.

Further the results did not show any considerable alteration in the volume of gastric juices suggesting that the anti ulcer effect was not mediated through its antacid action. In this context, it is of considerable importance to note that certain prostaglandins are able to protect the gastric mucosal lesions induced by ethanol without affecting the gastric acid secretion, an action called cyto protection. In the present investigation, though the leaves and fruits though failed to affect the volume of gastric juice, offered significant protection against ethanol induced gastritis and aspirin induced pyloric ligated ulcers. Because of the observed similarity in the effect of prostaglandins and sample extracts, it is worthwhile to suggest that the response may be due to cyto protection.

Tannins are local cicatrizant substances, not being absorbed by gastro intestinal tract and probably have anti ulcer action. The anti ulcerogenic effect of Linderae umbellatae was due to presence of condensed tannins [24]. Recent investigations have shown that the nutrients in foods and nutrient supplements were also associated with the reduction in the healing of ulcers. Vitamin $\mathrm{C}$ was thought to attenuate the deleterious effects of aspirin due to its anti oxidizing properties by reducing lipid per oxidation and cytokine release. Similarly zinc is also an important mineral for wound healing. Zinc at a dose of $3 \mathrm{mg}$ and $10 \mathrm{mg} / \mathrm{Kg}$ twice a day not only reduced the size and depth of ulcers but also promoted the regeneration of defective mucosa [25].

\section{Conclusion}

In the light of above observations it is proved on animal models that Solanum nigrum is anti gastritic and anti ulcerogenic. Such activity may explain why the plant is used locally in Tamilnadu for the treatment of ulcers. The protective action could be attributed to a combined action of cytoprotection, presence of anti oxidant vitamins, minerals, tannins and other phytochemicals. With further studies the specific active constituents may be indentified and their mechanism of action may be elucidated. A plant possessing both anti gastritic and anti ulcerative effects along with a combination of anti oxidant nutrients and phytochemicals is of great therapeutic importance as a preventive functional food.

\section{References}

[1] G.V. Satyavati, A.K. Gupta, and N Tandon, "Ocimum sanctum Linn(Tulsi)" In: Medicinal plants of India, Indian council of Medical Research. New Delhi, 1987, 27:574-575J.

[2] E. Adami, E. Marzz-Uberti, and C. Turba, "Pharmacological research on Gefarnate, a new synthetic isoprenid with an anti ulcer action", Archives International Pharmacodynamic et de therapie , 1964, 147:113-145.
[3] L.Barbara , R. Corinaldesi , M. Giorgi-Coniciato , L. Luchetta L, and G. Busca, "The mechanism of action of gefarnate in the light of latest data on digestive physiopathology", Current Medical research and opinion, 1974, 2: 399-410.

[4] R. Best, D.A. Lewis, and N. Nasser, "The anti ulcerogenic effect of unripe plantain banana (Musa spp)", British Journal of Pharmacology, 1984, 82:107-116.

[5] M.A.Jafri , Farah, K. Javed , and S. Singh, "Evaluation of gastric anti ulcerogenic effect of large cardamom (fruits of Amomum subulatum Roxb)", J Ethnopharmacology , 2001, 75(2-3):89-94.

[6] S. Maity , J.R. Vedasiromoni, and D.K. Ganguly, "Role of glutathione in the anti ulcer effect of hot water extract of black tea (Camellia sinensis)", Jpn J Pharmacol. 1998, 78(3):285-92

[7] J.M. Piper, W.A. Ray , J.R.Daugherty, and M.R. Griffin, "Cortico steroid use and peptic ulcer disease:Role of non steroidal anti-inflammatory drugs", Ann Intern Med, 1991, 114:735

[8] V.M. Gogate, "Ayurvedic Pharmacology and therapeutic uses of medicinal plants (Dravyagun vignyan)", Bharatiya vidya Bhavan, Mumbai, 1982, pp 675

[9] S.Sazabo , J.S.Trier, A. Beown, and J. Schnoor, "Increased vascular injury and permeability in gastric mucosal injury caused by ethanol in rats", Gastroenterology, 1985 , $88: 228-235$.

[10] V.L. Beach, and B.G. Steinetz, "Quantitative measurement of Evans Blue space in the tissues of rats; influence of 5 hydroxytryptamine antagonists and phenelizine on experimental inflammation”, J phar Exp. 1961, 131:400-406.

[11] H. Shay, S.A. Komarov , S.S.Fels, D. Meranze, M. Gruenstein, and H. Siplet, "A simple method for the uniform production of gastric ulceration", Gastroenterology, 1945, 5:43-61.

[12] S.K. Kulkarni, and R.K. Goel, "Gastric anti ulcer activity of UL-409 in rats”, Indian J of Exp Biology, 1996, 34: 683-688.

[13] J. B. Harbone, "Phytochemical methods- a guide to modern techniques of plant analysis", Chapman and Hall, New York, 1973, pp 55-178.

[14] N.Raghuramulu, N.K. Madhavan, and S. Kalyanasundaram, "A Manual of Laboratory Techniques," National Institute of Nutrition, Hyderabad, 1993, pp 80-81.

[15] AOAC, Official methods of analysis, Association of Official Analytical Chemists, $16^{\text {th }}$ edition, 1995.

[16] S. Ranganna, Handbook of Analysis and Quality Control for Fruit and Vegetable Products. $2^{\text {nd }}$ ed. Tata McGraw-Hill, New Delhi, 1986, pp 80-81.

[17] P.H. Guth , G. Paulsen, and H. Nagata, "Histological and micro circulatory changes in alcohol induced gastric lesions in rat: effect of prostaglandin cyto protection", Gastroenterology, 1984, 87:1083-1090.

[18] R. Hernandez-Munoz, C. Montiel-ruiz, and O. Vazquez-Martinez, "Gastric mucosal cell proliferation in ethanol-induced chronic mucosal injury is related to oxidative stress and lipid peroxidation in rats", Lab Invest. 
2000 80(8):1161-9.

[19] J.S. Lee, Y.K. Oh TY, Kim, J.H. Baik, S. SO , K.B. Hahm, and Y.J. Surh, "Protective effects of green tea polyphenol extracts against ethanol-induced gastric mucosal damages in rats: stress-responsive transcription factors and MAP kinases as potential targets", Mutat res. 2005, 579(1-2):214-24.

[20] K.F. Steiner, "Sucralfate (Ulcogant). The mechanism of action of a cytoprotective agent", Fortschr Med . 1983, 101(47-48):2197-200.

[21] S.J. Konturek, T. Brzozowski, J.Majka ,and K. Czarnobilski, "Role of nitric oxide and prostaglandins in sucralfate induced gastro protection", Eur J Pharmacol , 1992, 211(2):277-9

[22] S.J. Konturek, T. Brzozowski , J. Stachura , and J. Majka, "Role of neutrophils and mucosal blood flow in gastric adaptation to aspirin", Eur J Pharmacol. 1994, 253(1-2):107-14

[23] M.J. Parnaham , and K. Brune , "Therapeutic control of inflammatory diseases." Agents and Action, 1987, 21:316-319

[24] N. Ezaki, M. Kato, N. Takizawa, S.Morimoto, G. Nonaka, and I. Nishioka ,"Pharmacological studies on Linderae umbellatae Ramus IV: Effects of condensd tannin related compounds on peptic activity and stress induced gastric lesions in mice", Planta Medica, 1985, 51:34-38.

[25] M. Ito, T. Tanaka, and Y. Suzuki, "Effect of N(3-aminopropionyl)-L-histidinato zn (Z-103) on healing and hydrocortisone induced relapse of acetic acid ulcers in rats with limited food intake", Jpn J pharmacol. 1990, 52(4):513-21 